\title{
Editorial: Special Issue on Wireless Personal Communications 2006 Conference
}

\author{
Neeli Prasad • Antonio Rodrigues · fred harris
}

Published online: 22 May 2008

(C) Springer Science+Business Media, LLC. 2008

The WPMC 2006 conference was held in San Diego California on 17-20 September. This unique conference is a premier international symposium. Participants report on scholarly and commercial activity that spans a diverse range of cutting edge technologies supporting advanced wireless systems. The theme of the 2006 conference was "Seamless Interoperability and Convergence of Communication, Computing, and Multimedia in Fixed and Mobile environments". Papers were presented in many tracks including: Antennas and Propagation, Transmission Technologies, DSP, Wireless Access, Multimedia and Networks, Security, Wireless Sensors, Modeling/Simulation, Software Defined Radio and Satellite Communications.

At the end of the conference, the organizers, pleased with the high quality of the presented papers concluded that many of the papers deserved a wider range of exposure to the community. Uma Jha, the conference General Chair approached Springer, and suggested that a Special Issue of the Wireless Personal Communications Journal be assembled from the higher end conference papers. We invited a small number of authors to submit expanded versions of their papers to be reviewed for consideration in this special issue. The papers were culled from those that had made the top $7.5 \%$ of the original ranking process during the conference selection process. After many e-mails, re-writes, reviews, queries, sleepless nights, some hand wringing, and Solomon like spurts of wisdom and insight, we selected the papers that appear in this special double issue of the Journal. We are pleased to share with you the fruits of a process that started over a year ago with the initial call for papers and is now nearing its conclusion with the composition of this editorial commenting and introducing the good works of the many authors represented here. When the material leaves my computer, in transient to Springer, I will wish it good voyage knowing professionals will put the final touches to the process as they assemble this special issue.

N. Prasad · A. Rodrigues $\cdot$ f. harris $(\varangle)$

Department of Electrical Engineering, College of Engineering, San Diego State University,

5500 Campanle Drive, San Diego, CA 92182-1309, USA

e-mail: fharris@engineering.sdsu.edu 
The 18 papers selected for this double issue fall into the following broad areas: Antennae, Digital Signal Processing, MIMO, Networks, OFDMA, Propagation, Radio Location, and Synchronization. Short biographies and photos of the authors accompany each paper. The full list of paper titles and their authors are grouped in their common areas in the Table of Contents. 